\title{
The Impact of Large Investors on the Portfolio Optimization of Single-Family Houses in Housing Markets
}

\author{
Bilgi Yilmaz $^{1,2}$ (D) Ralf Korn $^{2} \cdot$ A. Sevtap Selcuk-Kestel ${ }^{1}$
}

Accepted: 11 January 2022 / Published online: 19 February 2022

(C) The Author(s) 2022

\begin{abstract}
As a consequence of the real estate market crash after 2008, large investors invested a significant amount of wealth into single-family houses to construct a portfolio of rental dwellings, whose income is securitized in the capital. In some local housing markets, these investors own remarkable numbers of single-family houses. Furthermore, their trading activities have resulted in a new investment strategy, which exacerbates property wealth concentration and polarization. This new investment strategy and its portfolio optimization inspire curiosity about its influence on housing markets. This paper first aims to find an optimal portfolio strategy by employing an expected utility optimization from the terminal wealth, which adopts a stochastic model that includes a variety of economic states to estimate house prices. Second, it aims to analyze the effect of large investors on the housing market. The results show the investment strategies of large investors depend on the balance among economic state, maintenance cost, rental income, interest rate and investment willingness of large investors to housing and their effect depends on the state of the economy.
\end{abstract}

Keywords Portfolio optimization · Housing market · Large investors · Regime switching processes

\section{Introduction}

The most recent global financial crisis triggered by the US housing market collapse in 2008 diminished the home-ownership rate almost in all countries. As a result, following the 2008 crisis, housing markets attracted some single-family real estate investors (such as large private equity firms, institutional investors, or real estate

$\triangle$ Bilgi Yilmaz

bilgiyilmaz07@gmail.com

1 Institute of Applied Mathematics, METU, 6800 Ankara, Turkey

2 Department of Mathematics, TU Kaiserslautern, 67653 Kaiserslautern, Germany 
investment trusts), who are called large investors, entered the stage with a new business model as an opportunity to construct a portfolio of single-family housing units in rental housing markets (Allen Marcus et al. 2018). Large investors are the biggest buyers in struggling local housing markets where house prices increase faster than healthy housing markets. Hence, contrary to the common belief, after the sub-prime mortgage crisis, large investors dominate local housing markets in return for benefiting from the leading edge of rising house prices and the rental income in their portfolio.

This new business form differs substantially from the usual business models in the housing market since large investors purchase vast numbers of single-family housing units and therefore, own a sizable large rental house portfolio. This conduces a new asset class that a broader group of investors may hold single-family rental houses in their portfolio without purchasing and managing houses by themselves. Contrary to the conventional belief on the inefficiency of large pools of single-family rental housing units due to their managing scattered-site housing units and cost as in the early eighties (Williams 1993), the large-scale buy-to-rent investment strategy in housing markets has emerged naturally in the last two decades (Mills 2019).

There are three major motivations behind the favorization of the new business model: (i) The large house inventory on housing markets following the 2008 crisis made it easier for investors to create geographically concentrated pools of almost identical properties as the unusually high number of single-family houses in the market creates an opportunity to summon a rental house portfolio. (ii) The tight mortgage financing policy gives large investors an advantage over small and local investors, and further spurring demand for rental housing units due to their more limited dependence on mortgage financing. (iii) The recent technological developments (cloud computing, personal mobile devices, and mobile internet connectivity and their integrity with the banking system) have allowed scattered-site property renovation, maintenance, and management in a more flexible and efficient manner (Mills 2019).

By relying on the efficient market hypothesis in the modern portfolio theory, we may claim the price of a house mirrors all available information in the housing market, which leads us to use the diffusion process as in the studies (Kau et al. 1995, 1990; Miranda-Mendoza 2010), and (Yilmaz and Selcuk-Kestel 2019). Therefore, it is likely the price of the house is indifferent to the type of purchaser whether the buyer is a large or an individual investor (Allen Marcus et al. 2018). However, the price diverts from its fundamental value and deviates across investor size because of factors such as high cost of information, lack of sufficient competition, high transaction and agency costs, and frictions in financing types. For instance, some investors may enjoy liquidity and transaction efficiencies (sophisticated targeting of potential acquisition houses, cash purchases, superior negotiation skills, and experience, etc.), and operational efficiencies (property and portfolio management expertise of investors) in local housing markets whose consumers may not have (Allen Marcus et al. 2018). On top of that, some investors might also enjoy the monopsony advantage during distressing periods and might be qualified to utilize their purchasing power and negotiation skills to purchase houses 
at a discount to their market value. On the other hand, purchases by large investors may increase the overall demand in local housing markets, deplete inventory of distressed local housing markets, and more importantly, cause an increase in house prices. Furthermore, large investors are primarily non-local at which they suffer from high search costs and informational disadvantages about local housing markets (Allen Marcus et al. 2018).

The impact of large investors on housing markets and their investment performance is significant for both local and small investors and inhabitants. They also create potential interest to accelerate the magnitude of recovery in local housing markets, particularly, with a large percentage of distressed houses (Allen Marcus et al. 2018). Furthermore, whether acquisition activities by large investors improve or suppress fundamental house prices, it is also critical for the overall economy since the recovery in housing markets is one of the leading indicators of national economic growth (Green 2003; Case et al. 2005; Leamer 2007; Ghent and Owyang 2010; Kydland et al. 2014).

A vast number of studies investigate the change in house prices at national and local levels. However, the number of studies examining the effect of large investors on housing markets is limited. The impact of a large investor on a local housing market typically depends on supply and demand behaviors as in fully competitive markets. On the supply side, developers construct new houses causing an increase in the number of housing units, types, and quality of houses in the local market. Whereas, the demand side sets the price of new houses to a competitive level within the existing prices and attractive to both investors and potential consumers who are eagerly seeking an attractive investment opportunity or domicile. Traditionally, theoretical studies emphasize that constructing new houses is generally likely to create both positive and negative externalities for house owners in local housing markets (Whitehead et al. 2015; Zahirovich-Herbert and Gibler 2014). In addition to the fiscal, social, and ecological benefits, new construction may generate benefits for adjoining private house owners as well. New houses may have positive spillover effects on existing neighborhoods by creating a more vibrant neighborhood as vacant lots become populated (Zahirovich-Herbert and Gibler 2014). If vacant lots create external dis-amenities through attracting dumping, allowing criminal use, or creating an eyesore, then building new houses progressively eliminates the external dis-economy, increases local population, improves the aesthetics of the local housing market, and increases surrounding property values (DeSalvo 1974). New constructions might be more aesthetically pleasing than unkempt lots or dilapidated houses, which improve the view of the market. However, such infill development may also cause an adverse effect on surrounding properties due to increased traffic flow, noise pollution, and reduction of green areas on the district (Malpezzi 1996). New houses may also compete directly with existing houses in the same housing market segment or indirectly through linked sub-markets, potentially reducing the values of nearby existing housing units by increasing supply while demand remains constant (Simons et al. 1998).

While most of the attention focuses on the effect of government expenditures and subsidies for city center redevelopment influence surrounding on house values and the impact of private residential construction on local housing markets, the effect of 
large investors on housing markets in this aspect remains an unresolved question. This paper aims to address this gap in the literature by employing stochastic differential equations (SDEs) and stochastic control methods to investigate the impact of large investors purchasing single-family houses for the rental business. On top of that, the impact of economic states on housing markets is taken into account using the Markov switching model. Therefore, the key ingredient and contribution of this paper are to examine the presence of large investors jointly with the effect of economic state on housing markets to maximize investors' wealth.

The organization of the paper is as follows: Sect. 2 introduces a theoretical framework for the economic environment of the investigated housing market. Furthermore, it includes preliminaries, proposed theorems along with their proofs to model the housing market with the effect of large investors. Sections 3 and 4 illustrates the numerical results of the proposed model, and concludes and states some possible extensions of the study, respectively.

\section{The Housing Market Structure}

In this study, the large investors as purchasers are assumed to utilize housing units in their portfolios only for business purposes. The context of large investors contains "corporate" investors. Corporate investors are the purchasers who intend to lease and/or resell the property without leasing or occupying it. On the other hand, individual investors are the investors where the buyer is not a corporation, and her legal mailing address appears for at least three transactions (Mills 2019).

Definition 1 A large investor is a buyer who has a corporate structure and does not intend to use the housing units for personal or company use.

In the context of the study, we assume that the objective of large investors is to find self-financing strategies in the long-term period that maximize their expected utility concerning their terminal wealth. To express house price dynamics, we define a triplet $(\Omega, \mathcal{F}, \mathbb{P})$ to be a filtered probability space with filtration $\mathbb{F}=\left(\mathcal{F}_{t \in[0, T]}\right)$ that satisfying the usual conditions for some fixed, but arbitrary time horizon $T \in(0, \infty)$. Now, consider a continuous-time finite-state Markov chain, $Y$, which represents the uncertainty of the economic state. Let $\epsilon=\left\{e_{1}, \ldots, e_{K}\right\}$ denotes the state space where $e_{k}$ is the basis of $\mathbb{R}^{K}$ and assume that the Markov chain, $Y$, has a generator $Q=\left(Q^{i j}\right)$ with a predetermined initial distribution denoted by $\pi=\left(\pi^{1}, \ldots, \pi^{K}\right)$.

Then, suppose there exists a large investor with a given initial wealth $x \in \mathbb{R}^{+}$in the market, and her objective is to find an investment strategy that maximizes her expected utility from her terminal wealth. Moreover, suppose that there are only two available investment instruments in the market: A bank account (or risk-free bond as a risk-free asset) and houses as risky assets. Therefore, the investor can invest in houses and a risk-free bond as the only available investment instruments in the market.

Assume the risk-free bond price process dynamics is given as in the usual form 


$$
d B_{t}=r B_{t} d t, \quad r>0, \quad \text { and } \quad t \geq 0 .
$$

Suppose $\alpha_{t} \in \mathbb{R}$ denotes the fraction of wealth invested into the houses at $t \in[0, T]$ whereas, $1-\alpha_{t}$, corresponds to the wealth that invested in the risk-free bond. Here, it is worth emphasizing that due to its nature, short selling of a house is not possible, which may create analytical difficulties. To avoid such obstacle, Assumption 1 is stated.

Assumption 1 Given $\alpha_{t} \in[0, L], L \in \mathbb{R}^{+}$for all $t \in[0, T]$ and $L$ is always chosen large enough to guarantee that the optimal solution of the corresponding portfolio problems is an interior point in the given interval if a finite optimal solution exists.

In the standard approach, a house price is assumed to evolve from a diffusion process whose mean and variance are determined by a two-state diffusion process (Kau et al. 1995, 1990). However, in this study, for the sake of simplicity, we employ a diffusion process specified by one state variable, which contains a Markov process that represents the state of the economy. A two-state diffusion process to define the evolution of house prices is more complex than the process we propose in this study. To present a model with simultaneous effect of a large investor and the state of the economy, we consider a diffusion process in the lead of the studies (Bauerle and Rieder 2004; Eksi and $\mathrm{Ku}$ 2017).

Let $H_{t}$ denote the real price of the house at time $t$, which is assumed to obey a diffusion process whose drift is a function of the current state of the economy and the fraction of wealth invested by the large investor. We propose the house price dynamics to be as follows:

$$
\begin{aligned}
\frac{d H_{t}}{H_{t}} & =\left[\mu\left(Y_{t}\right)+g\left(\alpha_{t}, m\right)\right] d t+\sigma d W_{t}, \\
H_{0} & =h_{0} .
\end{aligned}
$$

Here, the parameter $\sigma>0$ represents the volatility, $m$ is the maintenance cost, $W_{t}$ is a Brownian motion which is independent of the Markov chain $Y_{t}$, and $g(\cdot, \cdot)$ represents the impact of the large investor on the drift of the house price process. At this stage, it should be noted that $\mu\left(Y_{t}\right)=M Y_{t}$ with $M^{k}=\mu\left(e_{k}\right), 1 \leq k \leq K$, which is a consequence of the finite-state property of the Markov chain.

The joint impact of the large investor and maintenance are deliberately placed into the model since the value of a house increases with regular maintenance. More importantly, the provision of more and better houses accommodates more households, develops the appearance of the region, and hence, brings in new infrastructure, additional spending, and investments in local shops and services. Contrary to other commodities, these effects in the local housing market influence house price gradually. Consequently, the impact of the large investor is added to the drift of the process in Eq. (1). Here, it is worth emphasizing that if the large investor purchases a house from an underdeveloped zone, it requires her to spend a fraction of her wealth for maintenance. Therefore, the effect of maintenance cost on the house is added to the model. Clarifying the role of the investment effect and 
maintenance is especially crucial in the current social and political environment (Harding et al. 2007).

On the other hand, the case of volatility, $\sigma$, under partial information brings us to an exciting setting where actions of the investors create a trade-off between the increase in the controlled part of the drift and decrease in the precision of the estimates of the unobserved portion of the drift. However, such a setting is even technically acceptable since one investor's movements do not make a significant change in house price volatility.

The dynamics introduced in Eq. (1) indicate that the portfolio choice of the large investor in the housing market might be taken as a signal by the small and local investors. That is, in a local area, the portfolio choice of the large investor acts as a factor governing the drift term of the house price process. Note that we focus on the case with no impact on the diffusion of the house price process, which admits a unique solution provided that the functional $g(\cdot, \cdot)$ is sufficiently regular.

As an immediate consequence of Eq. (1), we make the following remark.

Remark 1 If the house price evolves from the stochastic process defined in Eq. (1), the following holds

(i) If $\mu\left(Y_{t}\right) \gg 0$, depending on its form the value of the impact functional $g(\cdot, \cdot)$ need not to be too large for yielding a decent return from houses.

(ii) If $\mu\left(Y_{t}\right) \approx 0$, the impact of the large investor may cause an increase in the house price. For instance, by depending on the form of $g(\cdot, \cdot)$, a substantial $\alpha_{t}$ and high maintenance can result in a decent return from houses.

To construct a portfolio within $[0, T]$, we assume a market where householders may sell without a cost, a fractional interest in their home. Here, the housing choice decision does not contain individual asset allocation. Further, we classify any purchaser that does not intend personal use for the housing unit as an investor. Thus, the term investors here includes corporate investors (Mills 2019). Under these assumptions, the portfolio dynamics of the wealth of the large investor satisfies,

$$
\frac{d X_{t}^{\alpha}}{X_{t}^{\alpha}}=\alpha_{t} \frac{d H_{t}}{H_{t}}+\left(1-\alpha_{t}\right) \frac{d B_{t}}{B_{t}}+\delta \alpha_{t} d t-m \alpha_{t} d t,
$$

where $\delta$ and $m$ denote the rate of rental income from the housing units and rate of maintenance cost of the investor, respectively. Note that the rental income and maintenance cost is considered as a dividend.

The investor benefits from renting the houses in her portfolio and thus has an income proportional to the investment amount to the housing. On the other hand, the investor has a cost due to maintenance, which is also proportional to housing investment. While the rental income has a positive effect on her total income, the maintenance yields an adverse impact on her total income as a cost.

Equivalently, we can write the wealth process as 


$$
\begin{aligned}
\frac{d X_{t}^{\alpha}}{X_{t}^{\alpha}} & =\left[\alpha_{t}\left(\mu_{t}\left(Y_{t}\right)+g\left(\alpha_{t}, m\right)\right)+\left(1-\alpha_{t}\right) r+\delta \alpha_{t}-m \alpha_{t}\right] d t+\alpha_{t} \sigma d W_{t}, \\
X_{0}^{\alpha} & =x>0 .
\end{aligned}
$$

To ensure the wealth process (2) is well defined, it is necessary to consider only investment strategies satisfying certain conditions given in Assumption 2.

Assumption 2 Let $X_{t}^{\alpha}$ be the wealth process defined in Eq. (2). Then, we call an investment strategy $\alpha_{t}$ admissible if $X_{t}^{\alpha}$ satisfies

$$
\int_{0}^{T}\left(\alpha_{s} X_{s}^{\alpha}\right)^{2} d s<\infty, \quad \text { a.s. }
$$

In modeling fully competitive markets, generally, it is assumed that investors are price takers. However, in the proposed model given with Eq. (1), this assumption is violated since we allow the large investor to influence the house price. Therefore, in such a case, we can not rely on the no-arbitrage condition provided for the classical models defined for financial markets. Under these considerations, we introduce the no-arbitrage condition on $g$ as follows:

Theorem 1 Let $H_{t}$ be the house price process introduced in Eq. (1). Given Assumptions 1 and 2 hold, and the function $g$ satisfies $\left|g\left(\alpha_{t}, m\right)\right| \leq C\left|1+\alpha_{t}\right|$ for a positive constant $C$, then, the market is arbitrage free.

Proof For an admissible strategy $\alpha_{t}$, suppose

$$
\theta(t)=\frac{\mu\left(Y_{t}\right)-r}{\sigma}, \quad 0 \leq t \leq T .
$$

It is clear that $\theta(t)$ is adapted to $\mathcal{F}_{t}$ since the Markov chain $Y_{t}$ is adapted and the volatility parameter $\sigma$ is constant. Using Girsanov's theorem, there exists an equivalent probability measure $\tilde{\mathbb{P}}$ under which

$$
\tilde{W}_{t}=W_{t}+\int_{0}^{t} \theta(s) d s
$$

is a Brownian motion. Here, $|\theta(t)| \leq \frac{\left|\mu\left(Y_{t}\right)+r\right|}{\sigma}$ and the Novikov condition is satisfied. Then, the Radon-Nikodym derivative is given by

$$
\frac{d \tilde{\mathbb{P}}}{d \mathbb{P}}=\exp \left\{-\int_{0}^{T} \theta(t) d W_{t}-\frac{1}{2} \int_{0}^{T} \theta^{2} t d t\right\} .
$$

Now, define

$$
L_{t}=\exp \left\{-\xi R_{t}\right\}, \quad \xi \in \mathbb{R}_{+},
$$

where 


$$
R_{t}=\int_{0}^{t} \alpha_{s}\left[\mu\left(Y_{s}\right)+g\left(\alpha_{s}, m\right)-r\right] d s+\int_{0}^{t} \alpha_{s} \sigma d W_{s}
$$

Then, $L_{t}$ can be written as

$$
L_{t}=\exp \left\{-\xi\left(\int_{0}^{t} \alpha_{s} g\left(\alpha_{s}, m\right) d s+\int_{0}^{t} \alpha_{s} \sigma d \tilde{W}_{s}\right)\right\} .
$$

By applying Itô's formula we obtain

$$
d L_{t}=L_{t}\left[\left(-\xi \alpha_{t} g\left(\alpha_{t}, m\right)+\frac{1}{2} \xi^{2} \alpha_{t}^{2} \sigma^{2}\right) d t-\xi \alpha_{t} \sigma d \tilde{W}_{t}\right] .
$$

Here, if $\xi>\frac{2 C}{\sigma^{2}}$, then the drift becomes negative $\left(L_{t}>0\right)$. By considering the integrability condition on $L_{t}$, we obtain $L_{t}$ as a super martingale on $\tilde{\mathbb{P}}$, hence

$$
\tilde{\mathbb{E}}\left[L_{T}\right] \leq \tilde{\mathbb{E}}\left[L_{0}\right]=1,
$$

where $\tilde{\mathbb{E}}$ denotes the expectation under $\tilde{\mathbb{P}}$ measure.

Now, suppose $\alpha_{t}$ to be an admissible strategy that satisfies

$$
\mathbb{P}\left(e^{-r T} X_{T}^{(\alpha)} \geq X_{0}^{(\alpha)}\right)=1,
$$

which corresponds to $\mathbb{P}\left(R_{T} \geq 0\right)=1$. From the equivalent property, $\tilde{\mathbb{P}}\left(R_{T} \geq 0\right)=1$. By Eq. (3) we have $\tilde{\mathbb{P}}\left(R_{T}=0\right)=1$, implying $\tilde{\mathbb{P}}\left(e^{-r T} X_{T}^{\alpha}=X_{0}^{\alpha}\right)=1$, which means $\alpha_{t}$ is not an admissible strategy. This final result contradicts with our assumption that $\alpha_{t}$ is an admissible strategy.

Suppose we are given a concave, increasing, and twice continuously differentiable utility function defined as $U: \mathbb{R}^{+} \longmapsto \mathbb{R}$. Then, the optimization problem of the large investor's value function, $V(x, i)$, in investing housing market becomes

$$
\begin{gathered}
V(x, i)=\max _{\alpha} \mathbb{E}^{x, i}\left[U\left(X_{T}^{(\alpha)}\right)\right] \\
\text { subject to } \\
X_{t}^{(\alpha)}=x, \quad Y_{t}=i .
\end{gathered}
$$

Throughout the study we consider the case that the investor is assumed to observe the true state of the economy. Accordingly, a portfolio strategy is admissible if $\alpha_{t} \in \mathcal{F}_{t}$ for all $t \in[0, T]$ and Assumptions 1 and 2 are hold.

Let $\mathcal{H}$ define the set of all admissible portfolio strategies. Then, under the logarithmic utility function, it is possible to solve the optimization problem for a general impact function, $g$, which is regular enough.

Proposition 1 Suppose that the impact function $g$ is continuously differentiable and the large investor has the utility function $U(x)=\log (x)$. Then, the optimal investment strategy is 


$$
\alpha^{*}(t, i)=\arg \max _{\alpha \in \mathcal{H}} \mathbb{E}^{x, i}\left[U\left(X_{T}^{(\alpha)}\right)\right]
$$

and furthermore, for all $(t, i) \in[0, T] \times \epsilon, \alpha^{*}(t, i) \in H_{i}^{\log }$ where

$$
H_{i}^{l o g}=\{0, L\} \cup\left\{l: M^{i}-r+g(l, m)+\delta l-m l+l\left(\frac{\partial g(l, m)}{\partial l}-\sigma^{2}\right)=0\right\} .
$$

Proof Given the wealth process dynamics in Eq. (2), we apply Itô's formula for the utility function $U(x)=\log (x)$ and obtain

$$
\begin{aligned}
& U\left(X_{T}^{(\alpha)}\right)=\log (x) \\
& \quad+\int_{t}^{T}\left(\alpha_{s}\left(\mu\left(Y_{s}\right)+g\left(\alpha_{s}, m\right)\right)+\left(1-\alpha_{s}\right) r+\delta \alpha_{s}-m \alpha_{s}-\frac{1}{2} \alpha_{s}^{2} \sigma^{2}\right) d s \\
& \quad+\int_{t}^{T} \alpha_{s} \sigma d W_{s} .
\end{aligned}
$$

For any admissible strategy $\alpha^{*} \in \mathcal{H}, \quad \int_{t}^{T} \alpha_{s}^{*} \sigma d W_{s}$ is well defined and $\mathbb{E}\left[\int_{t}^{T} \alpha_{s}^{*} \sigma d W_{s}\right]=0$ since it is a martingale. Hence, we have

$$
\begin{aligned}
\mathbb{E}^{x, i}\left[U\left(X_{T}^{(\alpha)}\right)\right]=\log (x)+\mathbb{E} & {\left[\int _ { t } ^ { T } \left(\alpha_{s}\left(\mu\left(Y_{s}\right)+g\left(\alpha_{s}, m\right)\right)+\left(1-\alpha_{s}\right) r\right.\right.} \\
+ & \left.\left.+\delta l-m \alpha_{s}-\frac{1}{2} \alpha_{s}^{2} \sigma^{2}\right) d s\right]
\end{aligned}
$$

Now, let us denote the integrand in Eq. (4) as

$$
f(s, l)=l\left(\mu\left(Y_{s}\right)+g(l, m)\right)+(1-l) r+\delta l-m l-\frac{1}{2} l^{2} \sigma^{2} .
$$

Then, from the continuity of the functional $g(\cdot, \cdot)$ for any $s \in[t, T], f(s, \cdot)$ is a continuous function defined on the compact set $[0, L]$. Hence, there exists a number in $[0, L]$ that maximizes $f(s, \cdot)$. More specifically, the maximizer satisfies $l: \frac{\partial f(s, l)}{\partial l}=$ 0 or $\{0, L\}$, which is $\alpha_{s}^{*} \in H_{i}^{\log }$.

Remark 2 One can extend Proposition 1 to the case where the impact function $g(\cdot, \cdot)$ is differentiable except for finitely many points in the domain $[0, L]$. Let $H^{0}$ denotes the set of the points where $g(\cdot, \cdot)$ is not differentiable. Then, Proposition 1 holds with the optimal solution $\alpha^{*}(t, i)=\left(H_{i}^{\log } \cup H^{0}\right)$.

To start with an easy and specific case application, consider the optimization problem under complete information with a linear impact function and logarithmic utility. Namely, for simplicity set the impact function as $g(\alpha, m)=\beta(\alpha+m)$ with $\beta>0$. Then, we give the following corollary as an immediate result of Proposition 1. 
Corollary 1 Suppose an investor with a utility function $U(x)=\log (x)$ and an impact function $g(\alpha, m)=\beta(\alpha+m)$ where $\beta>0$. Then, we have

$$
H_{i}^{l o g}=\left\{0, L,\left(\frac{M^{i}+\delta+(\beta-1) m-r}{\sigma^{2}-2 \beta}\right)^{+}\right\} .
$$

In particular, depending on the given set of model parameters we have the following cases:

(i) if $2 \beta-\sigma^{2}<0$, then, for all $(t, i) \in[0, T] \times \epsilon$, the optimal strategy is given by

$$
\alpha^{*}(t, i)=\left(\frac{M^{i}+\delta+(\beta-1) m-r}{\sigma^{2}-2 \beta}\right)^{+},
$$

and the value function has the following stochastic representation:

$$
V(t, x, i)=\log (x)+r(T-t)+\mathbb{E}^{x, i}\left[\int_{t}^{T} \frac{\left[\left(\mu\left(Y_{s}\right)+\delta+(\beta-1) m-r\right)^{+}\right]^{2}}{2\left(\sigma^{2}-2 \beta\right)} d s\right] .
$$

(ii) if $2 \beta-\sigma^{2} \geq 0$, then, for all $(t, i) \in[0, T] \times \epsilon$, the optimal strategy is given by

$$
\alpha^{*}(t, i)=L \mathbb{M}_{M^{i}+\delta+(\beta-1) m-r \geq-L\left(\beta-\frac{1}{2} \sigma^{2}\right)}
$$

and the value function in this case has the following stochastic representation:

$$
\begin{aligned}
V(t, x, i)=\log (x) & +(T-t)\left(\left(\beta-\frac{\sigma^{2}}{2}\right) L^{2}+r\right) \\
& +\mathbb{E}^{x, i}\left[L \int_{t}^{T}\left(\mu\left(Y_{s}\right)+\delta+(\beta-1) m-r\right) d s\right] .
\end{aligned}
$$

Remark 3 As a consequence of Corollary 1, we infer:

(i) If parameters satisfy $M^{i}+\delta+(\beta-1) m-r<0$, the solution is not an optimal solution for the housing market. This case occurs if the economy is in the bad state and the interest rate is high which an indication of an unfavorable housing market. The optimal strategy leads investors to have a positive bank account. Further, if the case in item $i$ ) occurs, the effect of large investors on housing markets is going to be significantly small as it is expected since $\frac{\sigma^{2}}{2}>\beta$.

(ii) If $\beta>\frac{\sigma^{2}}{2}$ the influence of the large investor on the house price is too high.

(iii) Corollary 1 also implies that there has to be a balance between rental income and maintenance. Hence, by using the balance, large investors may have a favorable investment environment. 
(iv) On the other hand, if the parameter condition in item ii) holds and if $M^{i}+\delta+(\beta-1) m-r \geq 0$, then the optimal action is to borrow as much as possible from the bank to purchase houses. This case clarifies that if the economy is in the good state, large investors may invest in housing by borrowing loans from the bank as much as possible.

In the following proposition, we consider the power utility function, $U(x)=\frac{1}{\theta} x^{\theta}, 0<\theta<1$, with the case with a linear impact function and obtain explicit results. This utility function gives constant relative risk aversion (CRRA) type preferences with risk aversion $(1-\theta) / x$. In this case, we address this problem by the dynamic programing approach. To this end, for any function $v \in C^{1,2}$ and $(t, x, i) \in[0, T] \times \mathbb{R}_{+} \times \epsilon, \alpha \in \mathcal{H}$, we define the differential operator

$$
\begin{aligned}
\mathcal{A}^{\alpha} v(t, x, i)= & \frac{\partial v(t, x, i)}{\partial t}+\frac{\partial v(t, x, i)}{\partial x} x\left(\alpha\left(M^{i}+g(\alpha, m)\right)+(1-\alpha) r+\alpha \delta-\alpha m\right) \\
& +\frac{1}{2} \frac{\partial^{2} v(t, x, i)}{\partial x^{2}} x^{2} \alpha^{2} \sigma^{2}+\sum_{j}(v(t, x, j)-v(t, x, i)) Q^{i j} .
\end{aligned}
$$

Here, from the standard verification result, we need to solve the following Hamilton-Jacobi-Belman (HJB) equation

$$
\begin{aligned}
& \sup _{\alpha} \mathcal{A}^{\alpha} v(t, x, i)=0 \\
& v(T, x, i)=\frac{1}{\theta} x^{\theta} \quad \text { for all }(x, i) \in \mathbb{R}_{+} \times \epsilon .
\end{aligned}
$$

Proposition 2 Suppose $U(x)=\frac{1}{\theta} x^{\theta}$ and $g(\alpha, m)=\beta(\alpha+m), \beta>0$ then,

(i) If $2 \beta-(1-\theta) \sigma^{2}<0$, the optimal strategy $\alpha^{*}$ is given by

$$
\alpha^{*}(t, i)=\left(\frac{M^{i}+\delta+(\beta-1) m-r}{(1-\theta) \sigma^{2}-2 \beta}\right)^{+},
$$

and $V(t, x, i)=\frac{1}{\theta} x^{\theta} u(t, i), \quad$ for all $(t, x, i) \in[0, T] \times \mathbb{R}^{+} \times \epsilon, \quad$ where $u(t, i)>0$, with $U(T, i)=1, i \in \epsilon$, is the unique solution of the following system of linear differential equations

$$
\frac{\partial u(t, i)}{\partial t}+a(i) u(t, i)+\sum_{j}(u(t, j)-u(t, i)) Q^{i j}=0,
$$

with $a(i)=\theta r+\frac{\theta\left(M^{i}+\delta+(\beta-1) m-r\right)^{2}}{2\left((1-\theta) \sigma^{2}-2 \beta\right)}$. Moreover, the value function has the following stochastic representation

$$
V(t, x, i)=\frac{x^{\theta}}{\theta} \exp (r \theta(T-t)) \mathbb{E}^{x, i}\left[\exp \left(\int_{t}^{T} \frac{\left[\theta\left(\mu\left(Y_{s}\right)+\delta+(\beta-1) m-r\right)^{+}\right]^{2}}{2\left((1-\theta) \sigma^{2}-2 \beta\right)} d s\right)\right] .
$$


(ii) If $2 \beta-(1-\theta) \sigma^{2} \geq 0$, the optimal strategy $\alpha^{*}$ is given by

$$
\alpha^{*}(t, i)=L 1_{M^{i}+\delta+(\beta-1) m-r \geq-L\left(\beta-\frac{1}{2}(\theta-1) \sigma^{2}\right)},
$$

and $V(t, x, i)=\frac{1}{\theta} x^{\theta} u(t, i), \quad$ for $\quad$ all $(t, x, i) \in[0, T] \times \mathbb{R}^{+} \times \epsilon$, where $u(t, i)>0$, with $U(T, i)=1, i \in \epsilon$, is the unique solution of the following system of linear differential equations

$$
\frac{\partial u(t, i)}{\partial t}+a(i) u(t, i)+\sum_{j}(u(t, j)-u(t, i)) Q^{i j}=0
$$

with $a(i)=\theta r+\theta L\left(M^{i}+\delta+(\beta-1) m-r\right)+\theta L^{2}\left(\beta+\frac{(\theta-1) \sigma^{2}}{2}\right)$. Moreover, the value function has the following stochastic representation

$$
\begin{aligned}
& V(t, x, i)=\frac{x^{\theta}}{\theta} \\
& \mathbb{E}^{x, i}\left[\exp \left(\theta(T-t)\left(L^{2}\left(\beta-\frac{(1-\theta) \sigma^{2}}{2}\right)+r\right)\right)\right. \\
& \left.+\theta L \int_{t}^{T} \mu\left(Y_{s}\right)+\delta+(\beta-1) m-r d s\right] .
\end{aligned}
$$

Proof It follows from the utility function form and the linearity of the wealth process for all $i \in\{1, \cdots, K\}$ that the value function can be written as $v(t, x, i)=\frac{1}{\theta} x^{\theta} u(t, i)$, for some $u \geq 0$ with $u(T, i)=1$. This yields

$$
\begin{aligned}
\frac{\partial v(t, x, i)}{\partial t} & =\frac{1}{\theta} x^{\theta} \frac{\partial u(t, i)}{\partial t}, \\
\frac{\partial v(t, x, i)}{\partial x} & =x^{\theta-1} u(t, i), \\
\frac{\partial^{2} v(t, x, i)}{\partial x^{2}} & =(\theta-1) x^{\theta-2} u(t, i) .
\end{aligned}
$$

Substituting these and $g(\alpha, m)=\beta(\alpha+m)$ in Eq. (5), we have

$$
\begin{gathered}
-r u(t, i)=\sup _{\alpha \in[0, L]}\left\{\alpha\left(M^{i}+\delta+(\beta-1) m-r\right) u(t, i)\right. \\
\left.+\alpha^{2}\left(\beta+\frac{\theta-1}{2} \sigma^{2}\right) u(t, i)\right\} \\
+\frac{1}{\theta} \frac{\partial u(t, i)}{\partial t}+\frac{1}{\theta} \sum_{j} Q^{i j}(u(t, j)-u(t, i)), \\
u(T, i)=1 \quad \text { for all } i \in\{1, \cdots, K\} .
\end{gathered}
$$

A necessary condition for the maximizer 


$$
2 \alpha\left(\beta+\frac{\sigma^{2}(\theta-1)}{2}\right) u(t, i)+\left(M^{i}+\delta+(\beta-1) m-r\right) u(t, i)=0
$$

is defined. Suppose $2 \beta<(1-\theta) \sigma^{2}$. These conditions together with $u(t, i)>0$ imply that the necessary conditions are also sufficient, i.e. the maximizer is given with Eq. (6). The positivity of $u(t, i)$ is also explained in Remark 4. After inserting the maximizer, we obtain Eq. (7). The differential equation given with Eq. (7) has a unique solution $u$. The Feyman-Kac representation of $u(t, i)$ is found as

$$
v(t, x, i)=\exp \{r \theta(T-t)\} \mathbb{E}^{x, i}\left[\exp \left\{\int_{t}^{T} \frac{\theta\left(\mu\left(Y_{s}\right)+\delta+(\beta-1) m-r\right)^{2}}{2\left((1-\theta) \sigma^{2}-2 \beta\right)} d s\right\}\right] .
$$

Infact, $v(t, x, i)=\frac{1}{\theta} x^{\theta} u(t, i)$ is a solution of the HJB Eq. (5), $v \in C^{1,2}$, and satisfies $|v(t, x, i)| \leq K(1+|x|)$ for an appropriate $K \in \mathbb{R}$. By applying a verification theorem, we obtain $v(t, x, i)$ as the optimal value function $V(t, x, i)$.

Next, suppose $2 \beta \geq(1-\theta) \sigma^{2}$. In this case the maximum is attained in one of the boundary points of the interval $[0, L]$. It is clear that our maximizer depends on the value of $\left(M^{i}+\delta+(\beta-1) m-r\right)$. Namely, $\alpha^{*}(t, i)=L$ for $M^{i}+\delta+(\beta-1) m-$ $r>-L\left(\beta-\frac{1}{2} \sigma^{2}\right)$ and $\alpha^{*}(t, i)=0$ for $M^{i}+\delta+(\beta-1) m-r<-L\left(\beta-\frac{1}{2} \sigma^{2}\right)$. Hence, by inserting these into Eq. (9) we obtain Eq. (8).

Remark 4 The representation of $u$ above implies that $u(t, i)$ is always positive provided that the given parameter restrictions are satisfied.

Remark 5 Proposition 2 suggests that for any parameter condition the current value function dominates the value function given in Bauerle and Rieder (2004). This means that the investor benefits from the presence of the price impact also in the case of power utility preferences.

\section{Numerical Experiments}

To illustrate the house price evaluation in terms of large investor and economic state proposed in Eq. (1), we employ a Monte Carlo simulation procedure. Under the assumption that there exists an operating large investor in the housing market whose utility function is the logarithmic function, we compute the optimal weight of the housing investment in the large investor portfolio. Then, we run a Monte Carlo simulation process to find expected house prices for trading days within a year. While doing this computation, we compute expected house prices by considering different economic states, investment willingness of the large investor, and house price volatility levels to observe their effect on the house prices.

Visual representation of the expected house prices (Figs. 1, 2, 3) and illustration of the house price paths over a one-year horizon (Figs. 4, 5) depict the similarity in the behavior of simulated and expected house prices in terms of the considered factors: the state of the economy, investment willingness of the large investor, and house price volatility. Here, it is also worth mentioning that we measure the 
investment willingness of the large investor via the slope, $\beta$, of the impact function $g$.

In the simulations, without loss of generality, we define the parameters given in Table 1. To compute expected house prices we used 10.000 simulations for trading days in one year. Here, note that we purposely consider three interest rates since the interest rate changes according to the state of the economy: Bad (0), Neutral (1), and Good (2). For instance, if the economy is in a bad state, the interest rate is going to be high due to its relationship with inflation. Besides, we also avoid analyzing the effect of rent amount and interest rate since they are both determined by the market, not by investors.

Figure 1, is a chart of the expected house price for the economic states and the bank account, where each time step corresponds to one of the trading days within the year. Figure 1 illustrates that if the economy is in the bad state, the house price does not increase as in the other two economic states which is a consequence of demand decrease due to the high-interest rate. Hence, investment in housing is not favorable during the bad economic state. The figure also reveals that investing in a bank account is favorable to housing during the bad economic state. However, even though the figure indicates that investing in housing is not favorable during the bad economic state, some of the large investors may have opportunistically acquired strategic single-family houses to gain market share and to diversify their rental income portfolio. On the other hand, if the economy is in the neutral or good state, housing investment is favorable since during both periods the interest rate is low compared to the bad economic state. Moreover, it is found that the large investor should borrow and invest in housing if the economy is in the good state since the return on the house price is higher than the return on the bank account. Hence, one of the most significant results is that the house price reacts to the economic state.

Figure 2 shows the effect of the large investor's investment willingness to the housing when the economy is in the neutral state. The graphs for the other two states

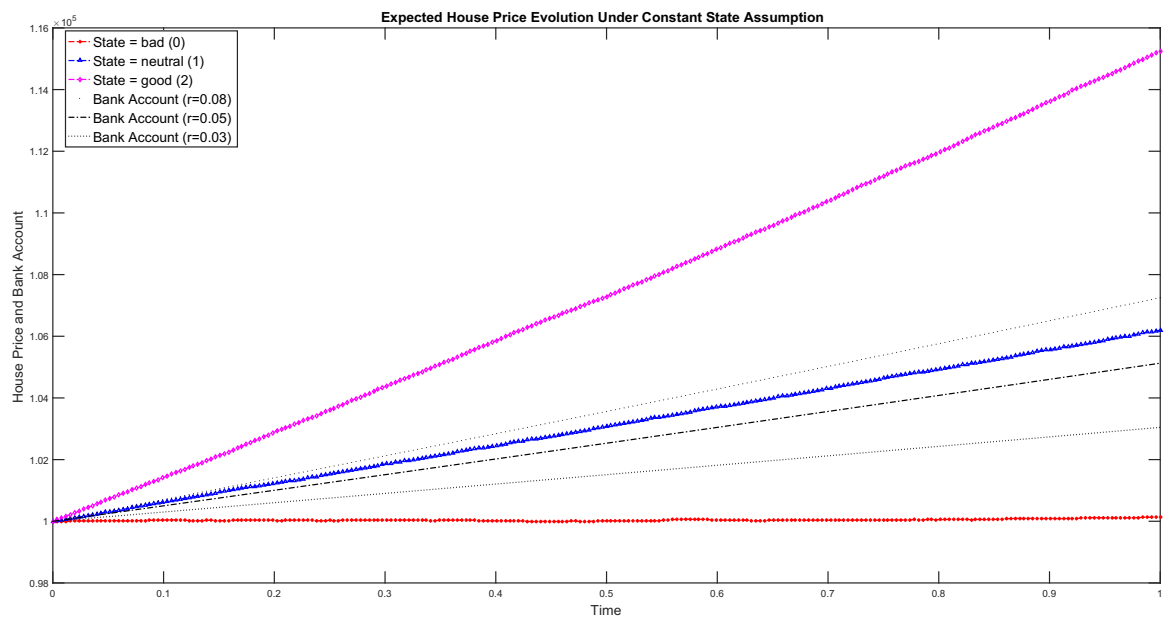

Fig. 1 The effect of the economic state on the house price 


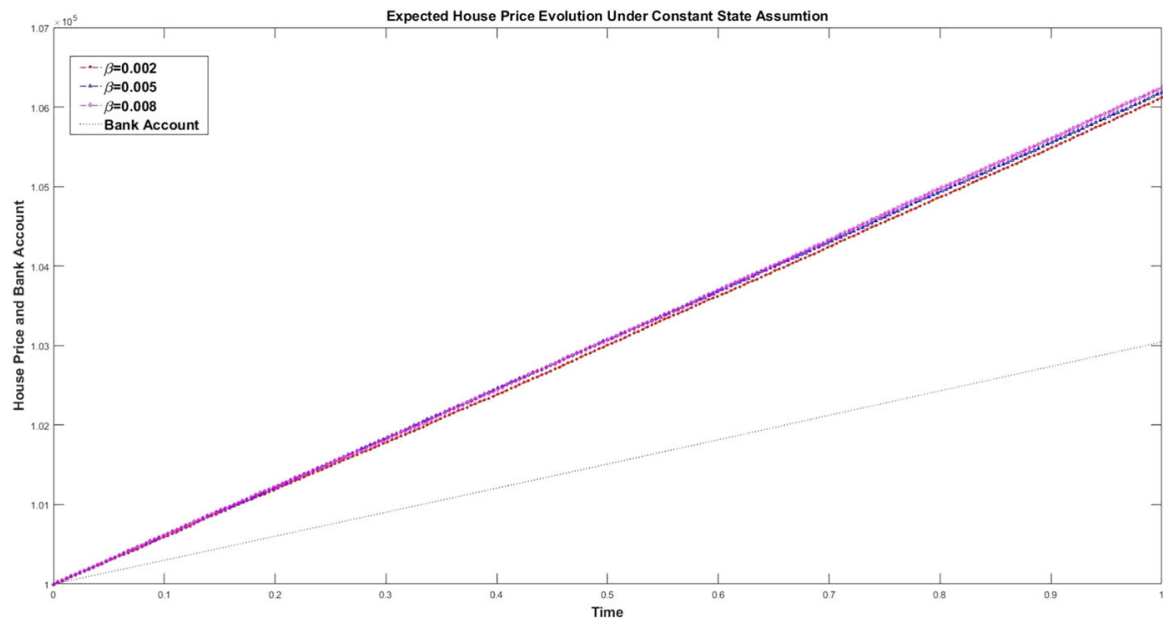

Fig. 2 The effect of $\beta$ on the house price under neutral economic state

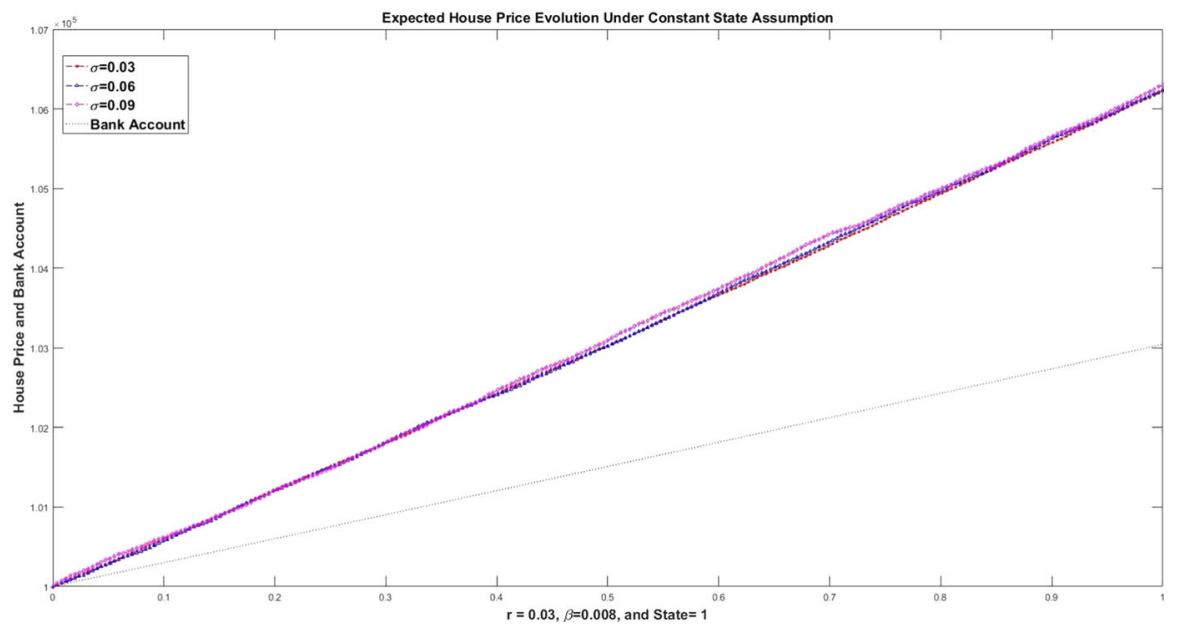

Fig. 3 The effect of the house price volatility on its price

of the economy are not given for two main reasons: (i) In a good state, the investor should invest as much as possible in housing, (ii) In the bad economic state housing investment is not favorable. As in Fig. 1, we see that if the economy is in the neutral state, the large investor should prefer investing in housing as much as possible because the willingness of the large investor leads to rising house prices. Expected house prices in terms of the large investor's investment willingness can be seen exerting a similar level of variability between 105.000 and 106.500. Here, note that the figure does not show a significant deviation among the house price paths since the volatility is too small $(\sigma=0.03)$. However, it is clear that that as the willingness 


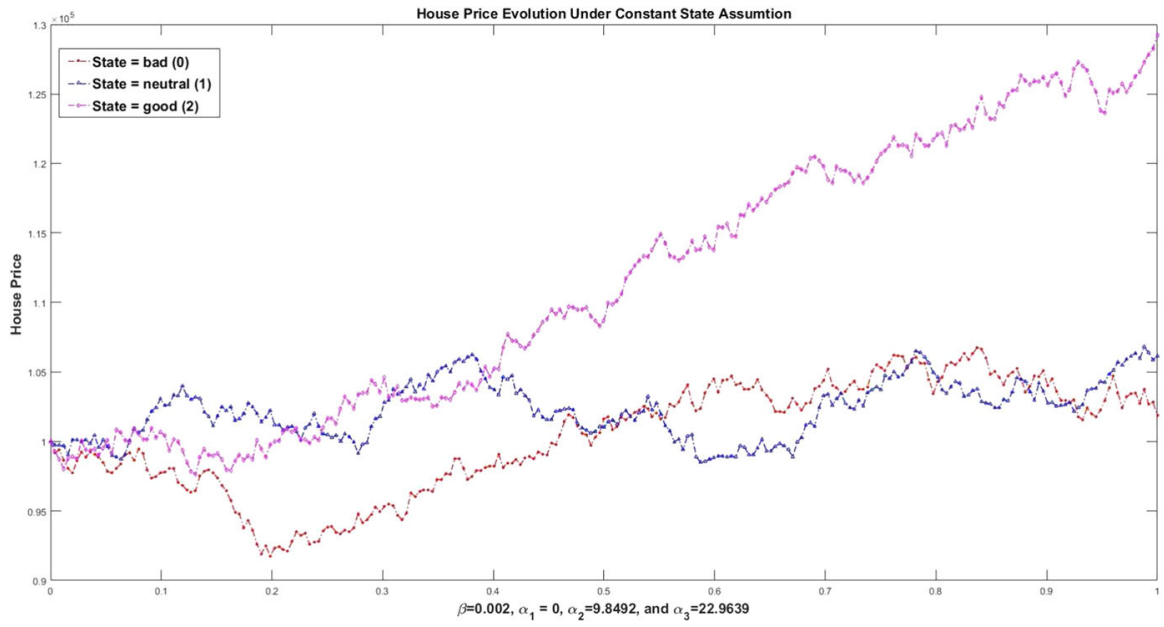

Fig. 4 House price evolution for all economic states under constant economic state assumption
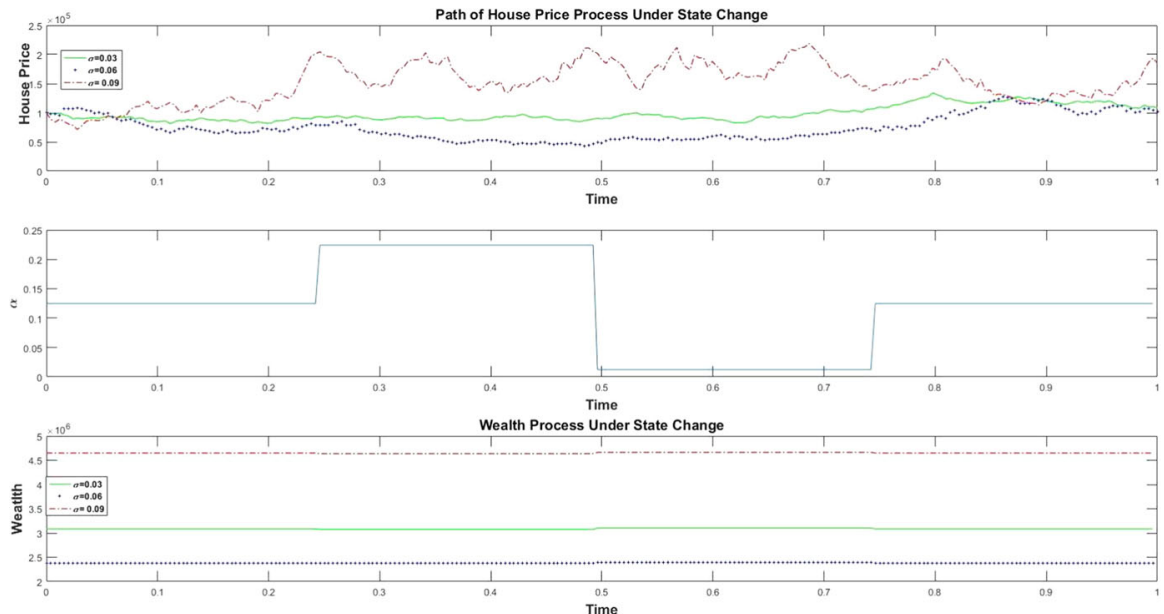

Fig. 5 The house price, investment weight and wealth process evolution for three volatility level under the non-constant economic state assumption

Table 1 The model parameters

\begin{tabular}{llllllll}
\hline$H_{0}$ & $\delta$ & $\mathrm{m}$ & $\mathrm{M}$ & $\sigma$ & $\mathrm{r}$ & $\beta$ & $Y_{i}$ \\
\hline 100,000 & 0.09 & 0.04 & 0.06 & 0.03 & 0.03 & 0.002 & 0 \\
& & & & 0.06 & 0.05 & 0.005 & 1 \\
& & & & 0.09 & 0.08 & 0.008 & 2
\end{tabular}


to investment increases, the house prices are increasing. It is a consequence of the increase in the housing demand.

The sensitivity of the house price to its volatility is shown in Fig. 3. As in the geometric Brownian motion, the value of the house is increasing when the volatility increases. However, the difference is not observable clearly due to the low volatility in the housing market ( $\sigma$ is chosen as $0.03,0.06$, and 0.09). We can not assign high volatility since the housing market is not as volatile as fully competitive markets.

Contrary to previous figures, Figs. 4 and 5 expose the paths for the house price for three volatility levels. The change in the states of the economy is taken into account while all other assumptions remain the same. Figure 4 explains the house price evolution for the economic states good, neutral and bad with the assumptions that the state of the economy is known at the beginning of the year and it remains constant within the year. However, Fig. 5 illustrates the price evolution of the house, the change in investment in housing, and the total wealth evolution of the large investor under the varying economic state. To compute the house price, here, we allow that the economic state may have changed twelve times in a year. The top figure illustrates the price evolution of house price, the figure in the middle illustrates the change in the investment into housing, and the figure in the bottom illustrates the total wealth evolution of the large investor. In this case, since the economic state is changed, the investment amount to the housing is also changed. Therefore, the large investor has to change his investment strategy when the economic state changes. As it is observed from the top figure, due to the reallocation, the deviation among the paths that represent house prices is higher than in Fig. 4. The figure in the middle, illustrates the change in the investment in housing $\alpha$. The portfolio of the investor is not changing very frequently. Hence, the total wealth portfolio is not varying significantly.

\section{Conclusion}

We investigate the effect of large investors on housing markets by maximizing the expected utility from the terminal wealth of these investors. The optimal investment problem of large investors is solved explicitly under the linear impact function, complete information, and $\log$ and power utility functions assumptions. We show that the optimal investment decisions depend on the balance among economic state, maintenance, rental income, interest rate, and willingness to invest in the large investor. The outcomes of this paper also show that investors should invest in the bond instead of investing in housing if the economy is in the bad state. However, if the economy is in the neutral and good state, investing in housing is a favorable investment compared to the bond. Besides, investors can improve their wealth by adjusting the maintenance cost. Moreover, the model clearly shows that in the good economic state, an investor should borrow as much as possible and invest in the housing market.

A key ingredient and contribution of this study is to identify the effect of large investor activities on housing markets and it guides investors in maximizing their wealth. We observe that large investors operating with log and power utility function assumptions may gain benefits from the price impact by choosing optimal 
investment strategies. As future work, we aim to investigate the effect of large investors having credit limitations and different interest rates for borrowing and lending assumptions.

Funding Open Access funding enabled and organized by Projekt DEAL.

Open Access This article is licensed under a Creative Commons Attribution 4.0 International License, which permits use, sharing, adaptation, distribution and reproduction in any medium or format, as long as you give appropriate credit to the original author(s) and the source, provide a link to the Creative Commons licence, and indicate if changes were made. The images or other third party material in this article are included in the article's Creative Commons licence, unless indicated otherwise in a credit line to the material. If material is not included in the article's Creative Commons licence and your intended use is not permitted by statutory regulation or exceeds the permitted use, you will need to obtain permission directly from the copyright holder. To view a copy of this licence, visit http:// creativecommons.org/licenses/by/4.0/.

\section{References}

Allen, M. T., Rutherford, J., Rutherford, R., \& Yavas, A. (2018). Impact of investors in distressed housing markets. The Journal of Real Estate Finance and Economics, 622-652.

Bauerle, N., \& Rieder, U. (2004). Portfolio optimization with Markov-modulated stock prices and interest rates. IEEE Transactions on Automatic Control, 49(3), 442-447.

Case, K.E., Quigley, J.M., \& Shiller, R.J. (2005). Comparing wealth effects: The stock market versus the housing market. Advances in Macroeconomics 5(1).

DeSalvo, J. S. (1974). Neighborhood upgrading effects of middle-income housing projects in New York City. Journal of Urban Economics, 1(3), 269-277.

Eksi, Z., \& Ku, H. (2017). Portfolio optimization for a large investor under partial information and price impact. Mathematical Methods of Operations Research, 86(3), 601-623.

Ghent, A. C., \& Owyang, M. T. (2010). Is housing the business cycle? Evidence from US cities. Journal of Urban Economics, 67(3), 336-351.

Green, R. K. (2003). Follow the leader: How changes in residential and non-residential investment predict changes in GDP. Real Estate Economics, 25(2), 253-270.

Harding, J.P., Rosenthal, S. S., \& Sirmans, C. (2007). Depreciation of housing capital, maintenance, and house price inflation: Estimates from a repeat sales model. Journal of Urban Economics, 61(2), $193-217$.

Kau, J. B., Keenan, D. C., Muller, W. J., III., \& Epperson, J. F. (1990). Pricing commercial mortgages and their mortgage-backed securities. The Journal of Real Estate Finance and Economics, 3(4), $333-356$.

Kau, J. B., Keenan, D. C., Muller, W. J., III., \& Epperson, J. F. (1995). The valuation at origination of fixed-rate mortgages with default and prepayment. The Journal of Real Estate Finance and Economics, 11(1), 5-36.

Kydland, F.E., Rupert, P., \& Sustek, R. (2014). Housing dynamics over the business cycle: An international perspective. Technical report, Working: Paper.

Leamer, E. E. (2007). Housing is the business cycle. National Bureau of Economic Research: Technical report.

Malpezzi, S. (1996). Housing prices, externalities, and regulation in U.S. metropolitan areas. Journal of Housing Research 7(2), 209-241

Mills, J., Molloy, R., \& Zarutskie, R. (2019). Large-scale buy-to-rent investors in the single-family housing market: The emergence of a new asset class. Real Estate Economics 0(0), 1-32

Miranda-Mendoza, F. (2010) An option-theoretic valuation model for residential mortgages with stochastic conditions and discount factors. Ph.D. thesis, Iowa State University

Simons, R., Quercia, R., \& Levin, I. (1998). The value impact of new residential construction and neighborhood disinvestment on residential sales price. Journal of Real Estate Research, 15(2), $147-161$. 
Whitehead, C. M., Sagor, E., Edge, A., \& Walker, B. (2015). Understanding the local impact of new residential development: A pilot study. London School of Economics and Political Science, LSE London: Technical report.

Williams, J. T. (1993). Agency and ownership of housing. The Journal of Real Estate Finance and Economics, 7(2), 83-97.

Yilmaz, B., \& Selcuk-Kestel, A. S. (2019). Computation of hedging coefficients for mortgage default and prepayment options: Malliavin calculus approach. The Journal of Real Estate Finance and Economics, 59(4), 673-697.

Zahirovich-Herbert, V., \& Gibler, K. M. (2014). The effect of new residential construction on housing prices. Journal of Housing Economics, 26, 1-18.

Publisher's Note Springer Nature remains neutral with regard to jurisdictional claims in published maps and institutional affiliations. 